\title{
Depression among medical students in Saudi medical colleges: a cross-sectional study
}

This article was published in the following Dove Press journal:

Advances in Medical Education and Practice

Hatem Alharbi

Abdulaziz Almalki

Fawaz Alabdan

Bander Haddad

Department of Psychiatry, College of Medicine, Al-Imam Muhammad Ibn Saud Islamic University, Riyadh, Kingdom of Saudi Arabia
Correspondence: Hatem Alharbi Department of Psychiatry, College of Medicine, Al-Imam Muhammad Ibn Saud Islamic University, 4250, Riyadh I4285 7902, Kingdom of Saudi Arabia Tel +966 | | 2037 7| |3 ext |8| Email hatemalharbi@outlook.com
Introduction: Major depressive disorder is a common mental disorder worldwide that has many clinical presentations and is associated with many diseases. The aim of this study is to assess the levels of depression among medical students in Saudi medical colleges.

Methods: A cross-sectional study with a convenience sample conducted in Saudi medical colleges. Patient Health Questionnaire-9 (PHQ-9) was used for screening and associated with sociodemographic characteristics.

Results: A total of 2,562 medical students from 20 universities were recruited into this study, and 1,572 (61.4\%) of the participants were females and 990 (38.6\%) were males. Depression symptoms are found to be associated with college years, living conditions and smoking status $(P<0.05)$.

Conclusion: High levels of depression symptoms were found among Saudi medical students (83.4\%). Students in the first years of college should be screened for depression, while education and support for medical students in these years are essential.

Keywords: depression, medical students, Saudi Arabia, medical education

\section{Introduction}

Depression is a normal physiological effect that can be experienced after an emotional, pathological, or even physical problem, but if it remains for a long time and affects the function of a person, it will develop into a mental disorder or more specifically depression, which is a cause of death worldwide. ${ }^{1}$ Major depressive disorder is a common mental disorder worldwide, which has many clinical presentations and is associated with many diseases. Physicians often fail to diagnose it, and it is usually missed. ${ }^{2}$ Approximately 300 million people worldwide are suffering from depression, and women are affected more than men. Disability and impairment of a person's ability to function normally at work, home, or taking part in community activities appear to be some of the symptoms of depression. ${ }^{3}$ People who live in poverty are two and half times more prone to develop major depressive disorder than people above the poverty level. Major depressive disorder is associated with an increased rate of chronic disease and the burden on health care services. ${ }^{4}$ Visits to a physician's office for depression estimated to be $10.4 \%$ of all visits. ${ }^{5}$ Patient Health Questionnaire-9 (PHQ-9) is a screening tool for establishing major depressive disorder based on the diagnostic criteria from the Diagnostic and Statistical Manual of Mental Disorders, Fourth Edition (DSM-IV). It is a questionnaire with nine items; each item scores $0-3$, and the total score is from 0 to 27 points. However, the outcomes of PHQ-9 do not diagnose depression. The 
questionnaire is a useful and reliable tool in terms of data validity. Gender is not identified or differentiated to avoid any bias to be established. ${ }^{6}$

Prevalence of depression among residents' physicians was 28\%. A systematic review included studies between 1963 and 2015 , involving 17,560 physicians. ${ }^{7}$ A cross-sectional study in 2009 showed a prevalence of $12 \%$ among physicians. ${ }^{4}$ The lifetime prevalence of depression is $19 \%$ for female physicians and $12 \%$ for male physicians. The suicide rates were investigated by a systematic review of 14 studies from 1963 to 1991, which showed higher rates of suicide among physicians compared to the general population. ${ }^{8}$

Medical students are known to experience stress during their 6 years of medical education, and stress was shown to decrease the quality of life and academic achievement. The stress that the medical students experience was determined to be associated with depressive symptoms, and $30 \%$ of the students reported depressive symptoms. ${ }^{9}$ Medical students are at high risk of developing depression or depressive symptoms, and there was approximately $17 \%$ increase in the number of students developing depressive symptoms from the first year to the third year, indicating that depression in a medical student is accumulative and the disease or symptoms increase over time if not diagnosed and treated effectively. ${ }^{10}$ Saudi medical students have a higher risk of developing depressive symptoms than other specialties because of personal, family, and social pressure that the doctors must be the best at everything. According to the results of the study, the data showed that medical students had a $25 \%$ higher depression rate than the people in other specialties. ${ }^{11}$ Prevalence of stress was 57\% among Saudi medical students. ${ }^{12}$ Another study carried out in King Faisal University, Saudi Arabia, found that the prevalence of depression was $16 \%$ among Saudi medical students. ${ }^{13}$

The objective of this study was to assess the prevalence of depression among medical students in Saudi Arabia since no large samples have been acquired through research so far to measure the effect of depression in the country.

\section{Methods}

This is a cross-sectional study with a convenience sample conducted in Saudi medical colleges using a multi-item questionnaire over a 2-month period (April and May 2018).

PHQ-9 was used, which contained nine questions based on DSM-IV. The questions are arranged as Likert items and graded from 0 to 3 (not at all, several days, more than half the days, and nearly every day). The Likert items are computed in a total score out of 27 categorized in a diagnostic algorithm where a score of 5-9 is considered mild,
10-14 moderate, $15-19$ moderately severe and $\geq 20$ is severe depression. The sociodemographic questions are related to gender, age, marital status, college year, nationality, smoking status, and living conditions. The reliability and validity of the Arabic version have been tested in a previous study conducted in Saudi Arabia. ${ }^{14}$

A team of 27 data collectors from 20 universities have been recruited to collect the data from the medical students in their universities. Initially, we aimed for two data collectors per university to cover both male and female students, but the number of volunteers for data collection was low. Later on, each data collector had a hard copy of the questionnaire to collect the responses and submitted it through the electronic form for data analysis. The participation in this study is voluntary, and completion of the questionnaire is considered as an informed consent.

Medical students who missed to answers the questions were excluded from this study.

Data analysis was performed using SPSS V23.0. Descriptive statistics were expressed as mean $\pm \mathrm{SD}$. Chi-squared test was used to determine $P$-values associated with sociodemographic factors. The institutional review board approval was obtained from Al-Imam Muhammad Ibn Saud Islamic University by research ethics committee, and the research was conducted in accordance with the Declaration of Helsinki.

\section{Results \\ Demographic data}

A total of 2,562 medical students from 20 universities were recruited into this study, and 1,572 (61.4\%) of the participants were females and $990(38.6 \%)$ were males, of whom 52 students excluded because of missing answers. The mean age was 22.05 years, and majority of them are from Saudi and single (96.1\% and $92.4 \%$, respectively). A total of $85.2 \%$ of medical students never smoked and $84.2 \%$ of students live with their families. Students from all the years participated in this study: year 1, 19.5\%; year 2, 21.8\%; year 3, 19.3\%; year 4, 21\%; and year 5, 18.4 (Table 1).

Twenty of 27 universities from all geographical regions of Saudi Arabia were involved in this study, and Jazan University shared the biggest number of contributions with 227 participants $(8.9 \%)$, and the least involvement was from Princess Nora bint Abdul Rahman University with 51 participants (2\%; Table 2$)$.

\section{Depression scores}

A total of $66.6 \%$ of the males and $87.6 \%$ of the females showed various levels of depression, starting from mild to 
Table I Demographic data of the participants

\begin{tabular}{|l|l|}
\hline Sociodemographic characteristics & $\mathbf{n ~ ( \% )}$ \\
\hline Gender & 2,562 \\
Male & $990(38.6)$ \\
Female & $1,572(61.4)$ \\
\hline Age, years ( \pm SD) & $22.05 \pm 1.98$ \\
\hline Marital status & \\
$\quad$ Single & $2,367(92.4)$ \\
Married & $195(7.6)$ \\
\hline College year & \\
Year I & $499(19.5)$ \\
Year 2 & $559(21.8)$ \\
Year 3 & $494(19.3)$ \\
Year 4 & $539(21)$ \\
Year 5 & $471(18.4)$ \\
\hline Nationality & \\
Saudi & $2,463(96.1)$ \\
Non-Saudi & $99(3.9)$ \\
\hline Living conditions & \\
With family & $2,518(84.2)$ \\
With relatives & $111(4.3)$ \\
Alone & $24 I(9.4)$ \\
Undetermined & $52(2)$ \\
\hline Smoking & \\
Never smoked & $2,182(85.2)$ \\
Previously smoked & $160(6.2)$ \\
Smoking & $220(8.6)$ \\
\hline
\end{tabular}

Table 2 Universities included in the study

\begin{tabular}{|l|l|}
\hline University & n (\%) \\
\hline Tabuk University & $165(6.4)$ \\
\hline Jazan University & $227(8.9)$ \\
\hline Al-Rayan Colleges & $53(2.1)$ \\
\hline Batterjee Medical College & $100(3.9)$ \\
\hline Imam Abdulrahman Bin Faisal University & $223(8.7)$ \\
\hline Princess Nora bint Abdul Rahman University & $5 \mathrm{I}(2.0)$ \\
\hline Najran University & $202(7.9)$ \\
\hline Prince Sattam Bin Abdulaziz University & $65(2.5)$ \\
\hline Taif University & $100(3.9)$ \\
\hline Al Maarefa Colleges & $101(3.9)$ \\
\hline Al-Imam Muhammad Ibn Saud Islamic University & $100(3.9)$ \\
\hline King Khalid University & $100(3.9)$ \\
\hline King Faisal University & $171(6.7)$ \\
\hline Qassim University & $184(7.2)$ \\
\hline University of Hail & $109(4.3)$ \\
\hline King Saud bin Abdulaziz University for Health Sciences & $113(4.4)$ \\
\hline Taibah University & $86(3.4)$ \\
\hline Ibn Sina National College for Medical Studies & $149(5.8)$ \\
\hline King Abdulaziz University & $183(7.1)$ \\
\hline Northern Borders University & $80(3.1)$ \\
\hline Total & $2,562(100)$ \\
\hline
\end{tabular}

severe stage of depression (total score, $>4$ ). Of both genders, $53.7 \%$ of them showed moderate severity and above levels of depression (total score $>9$ ). $P$-value of 0.001 is considered statistically significant (Table 3 ).
Depression symptoms are found to be associated with college years, living conditions and smoking status $(P$-value $<0.05)$, while there was no association in gender or nationality ( $P$-value $>0.05$; Table 4$)$

\section{Discussion}

Our aim was to determine the prevalence of depression among medical students in Saudi Arabia. The prevalence of depression in our sample was high. The high frequency of mild-moderate depression (55.9\%) was similar to that of other studies among medical students. ${ }^{15}$ Most of the medical students reported depressive symptoms (83.4\%). In another study that was carried out in Poland showed that medical students with depression did not reach $60 \%$, which is different from our data since the depressive symptoms in Saudi Arabia are high. ${ }^{16}$ This peak of depression in Saudi Arabia could be attributed to many factors such as competency for limited seats of residency programs among graduated students, yearly updating requirements for residency application, and family and social pressure. Also, in Oman, the severe level of depression in medical students was $13.8 \%$, whereas it was $11.6 \%$ in our study, which is quite similar between the two studies since the two countries share the same environment for medical students. ${ }^{17}$ We did not find any difference in depression severity among male and female medical students, which is a difference in comparison to other studies that found that female students are more vulnerable to depressive symptoms. ${ }^{18}$ This could be a plausible research sample since females in Saudi Arabia have a different sociodemographic morphology than Western countries. A study that was published in Croatia showed that depression level in females was $54.9 \%$ and in males was $59.3 \%$, and in our study, there was very little difference, which was not even $2 \% .{ }^{16}$ We found that there was no difference in frequency of reporting depressive symptoms and the state of the marital status of the student (single or married).

The frequency of reporting depressive symptoms gradually decreased with advancing toward the fifth year $(P=0.034)$. Another study carried out in India showed the same pattern as found in our study in decreasing depressive symptoms from first year to the fifth year, but there was a surprising increase in the third year in depressive symptoms, unlike our data where the numbers decreased starting from year 1 to year $5 .{ }^{19}$ This could be explained by confidence in the level of knowledge or even by the fact that they are in their final years of medicine, in comparison with those who just started college especially when a high grade point average is a major goal. 
Table 3 Depression severity in relation with gender

\begin{tabular}{|c|c|c|c|c|c|c|}
\hline \multirow[b]{2}{*}{ Gender } & \multicolumn{5}{|c|}{ Depression severity } & \multirow[b]{2}{*}{$P$-value ${ }^{a}$} \\
\hline & $\begin{array}{l}\text { None-minimal } \\
(0-4), n(\%)\end{array}$ & Mild (5-9) & $\begin{array}{l}\text { Moderate } \\
(10-14)\end{array}$ & $\begin{array}{l}\text { Moderately } \\
\text { severe (15-19) }\end{array}$ & $\begin{array}{l}\text { Severe } \\
(20-27)\end{array}$ & \\
\hline Male & $233(23.4)$ & $299(30.4)$ & $242(24.5)$ & $128(12.9)$ & $88(8.8)$ & \multirow[t]{3}{*}{0.001} \\
\hline Female & $196(12.4)$ & $46 I$ (29.3) & $429(27.3)$ & $277(17.6)$ & 209 (I3.2) & \\
\hline Total & $429(16.7)$ & $760(29.7)$ & 67I (26.2) & 405 (15.9) & $297($ (II.6) & \\
\hline
\end{tabular}

Note: abased on chi-squared test.

Table 4 Presence of depression symptoms associated with sociodemographic factors

\begin{tabular}{|c|c|c|c|}
\hline \multirow[t]{2}{*}{$\begin{array}{l}\text { Sociodemographic } \\
\text { characteristics }\end{array}$} & \multicolumn{2}{|c|}{$\begin{array}{l}\text { Presence of depression } \\
\text { symptoms }\end{array}$} & \multirow[t]{2}{*}{$P$-value ${ }^{a}$} \\
\hline & Yes & No & \\
\hline $\begin{array}{l}\text { Marital status } \\
\text { Single } \\
\text { Married }\end{array}$ & $\begin{array}{l}1,309(83.3) \\
122(83.1)\end{array}$ & $\begin{array}{l}396(16.7) \\
33(16.9)\end{array}$ & 0.233 \\
\hline $\begin{array}{l}\text { College years } \\
\text { Year I } \\
\text { Year } 2 \\
\text { Year } 3 \\
\text { Year } 4 \\
\text { Year } 5 \\
\end{array}$ & $\begin{array}{l}439(88) \\
480(85.9) \\
418(84.6) \\
44 I(81.8) \\
355(75.4) \\
\end{array}$ & $\begin{array}{l}60(12) \\
79(14.1) \\
76(15.4) \\
98(18.2) \\
116(24.6)\end{array}$ & 0.034 \\
\hline $\begin{array}{l}\text { Nationality } \\
\text { Saudi } \\
\text { Non-Saudi } \\
\end{array}$ & $\begin{array}{l}2,043(82.9) \\
99(90.9)\end{array}$ & $\begin{array}{l}420(17.1) \\
9(9.1)\end{array}$ & 0.097 \\
\hline $\begin{array}{l}\text { Living condition } \\
\text { With family } \\
\text { With relatives } \\
\text { Alone } \\
\text { Undetermined }\end{array}$ & $\begin{array}{l}\text { I,792 (83) } \\
9 \mathrm{I}(82) \\
24 \mathrm{I}(88.8) \\
36(69.2)\end{array}$ & $\begin{array}{l}366(17) \\
20(18) \\
27(11.2) \\
16(30.8)\end{array}$ & 0.004 \\
\hline $\begin{array}{l}\text { Smoking status } \\
\text { Never smoked } \\
\text { Previously smoked } \\
\text { Smoking }\end{array}$ & $\begin{array}{l}\text { I,804 (82.7) } \\
\text { I } 40(87.8) \\
\text { I } 78(80.9)\end{array}$ & $\begin{array}{l}378(17.3) \\
20(12.5) \\
42(19.1)\end{array}$ & 0.008 \\
\hline
\end{tabular}

Note: ${ }^{\text {aBased }}$ on chi-squared test.

Students who live alone were found to have a slightly higher frequency of reporting depressive symptoms in comparison to students living with their families or relatives. Being alone is a factor that differs in social life as well as in having depressive symptoms. This was demonstrated in the results of our study, which showed that $88 \%$ of participants who lived alone developed depression, but nearly half of this percentage was written in another study which shared the main idea in regards to depression in medical students, which raised a question "does the region differ that much?". ${ }^{20}$ There was no significant difference between the students who smoke and those who never smoked and ex-smoker students in the frequency of reporting depressive symptoms. Smoking did not play a role in the equation as in a different study that was carried out in 2015, which found that the difference is nearly $3 \%$ while in the data we collected the smoking student and ex-smoker difference was between 7\% higher in ex-smokers but in relation to the non-smoking students the difference was only $2 \% .{ }^{19}$

\section{Conclusion}

High levels of depression symptoms were found among medical students (83.4\%) in Saudi medical colleges. Students in the first year of college should be screened for depression, while education and support for them at these years are essential.

This study was limited to measure the prevalence of depression with sociodemographic factors. Further studies should include possible contributory factors for depression, particularly the infrastructure of the educational system and any other comorbid illnesses.

\section{Acknowledgments}

We acknowledge the following 27 data collectors for their efforts: Abdulaziz Al-Turki, Abeer Aodh, Albatoul Almulhim, Amina Salhi, Amjaad Algethami, Anwar Al-khalifah, Fahad Abualnassr, Fatima Alturki, Fatimah Al khabbaz, Hajer Alshamrani, Hessa Aljubair, Ibrahim Almajed, Mahdi Alzamanan, Malak Alkaf, Mariah Alamri, Marwan Bader, Mawaddah Al-akdar, Meshal Alharbi, Mohammad Alhakamy, Musaab Alsaad, Omniyyah Alnahyah, Rayhana Al-Rasheedi, Sara Alshahwan, Sarah Rayyani, Sarah Lubbad, Wafaa Alkaf, and Waled Albalawi.

\section{Disclosure}

The authors report no conflicts of interest in this work.

\section{References}

1. Richards D. Prevalence and clinical course of depression: a review. Clin Psychol Rev. 2011;31(7):1117-1125.

2. Sajjadi H, Mohaqeqi Kamal SH, Rafiey H, Vameghi M, Forouzan AS, Rezaei M. A Systematic review of the prevalence and risk factors of depression among Iranian adolescents. Glob J Health Sci. 2013;5(3).

3. World Health Organization. Depression [Internet]; 2018. Available from: http://www.who.int/en/news-room/fact-sheets/detail/depression. Accessed August 6, 2018.

4. Pratt LA, Brody DJ. Depression in the U.S. household population, 2009-2012. NCHS data brief, no 172. Hyattsville, MD: National Center for Health Statistics; 2014. 
5. Rui P, Okeyode T. National Ambulatory Medical Care Survey: 2015 State and National Summary Tables. 2015.

6. Manea L, Gilbody S, Mcmillan D. A diagnostic meta-analysis of the Patient Health Questionnaire-9 (PHQ-9) algorithm scoring method as a screen for depression. Gen Hosp Psychiatry. 2015;37(1):67-75.

7. Mata DA, Ramos MA, Bansal N, et al. Prevalence of depression and depressive symptoms among resident physicians. Surve Anesthesiol. 2016;60(4):146

8. Center C, Davis M, Detre T, Ford D, et al. Confronting depression and suicide in physicians: a consensus statement. JAMA. 2003;289(23): 3161-3166.

9. Haldorsen H, Bak NH, Dissing A, Petersson B. Stress and symptoms of depression among medical students at the University of Copenhagen. Scand J Public Health. 2014;42(1):89-95.

10. Ludwig AB, Burton W, Weingarten J, Milan F, Myers DC, Kligler B. Depression and stress amongst undergraduate medical students. $B M C$ Med Educ. 2015;15(1):141.

11. Alfaris EA, Naeem N, Irfan F, Qureshi R, van der Vleuten C. Student centered curricular elements are associated with a healthier educational environment and lower depressive symptoms in medical students. $B M C$ Med Educ. 2014;14(1):192.

12. Abdulghani $H$ [Internet]. Stress and depression among medical students: A cross sectional study at a medical college in Saudi Arabia; 2018 Available from: http://pjms.com.pk/issues/janmar08/article/article2 html. Accessed August 6, 2018.
13. El-Gilany AH, Amr M, Hammad S. Perceived stress among male medical students in Egypt and Saudi Arabia: effect of sociodemographic factors. Ann Saudi Med. 2008;28(6):442-448.

14. Becker $\mathrm{S}, \mathrm{Al}$ Zaid $\mathrm{K}, \mathrm{Al}$ Faris $\mathrm{E}$. Screening for somatization and depression in Saudi Arabia: a validation study of the PHQ in primary care. Int J Psychiatry Med. 2002;32(3):271-283.

15. Honney K, Buszewicz M, Coppola W, Griffin M. Comparison of levels of depression in medical and non-medical students. Clin Teach. 2010;7(3):180-184.

16. Seweryn M, Tyrała K, Kolarczyk-Haczyk A, Bonk M, Bulska W, Krysta $\mathrm{K}$. Evaluation of the level of depression among medical students from Poland, Portugal and Germany. Psychiatr Danub. 2015;27(Suppl 1): 216-222.

17. Sidana S, Kishore J, Ghosh V, Gulati D, Jiloha R, Anand T. Prevalence of depression in students of a medical college in New Delhi: A crosssectional study. Australas Med J. 2012;5(5):247-250.

18. Puthran R, Zhang MW, Tam WW, Ho RC. Prevalence of depression amongst medical students: a meta-analysis. Med Educ. 2016;50(4):456-468.

19. Iqbal S, Gupta S, Venkatarao E, Venkatarao E, gupta S. Stress Anxiety. Stress, anxiety and depression among medical undergraduate students and their socio-demographic correlates. Indian J Med Res. 2015;141(3):354.

20. Haldorsen H, Bak NH, Dissing A, Petersson B. Stress and symptoms of depression among medical students at the University of Copenhagen. Scand J Public Health. 2014;42(1):89-95.
Advances in Medical Education and Practice

\section{Publish your work in this journal}

Advances in Medical Education and Practice is an international, peerreviewed, open access journal that aims to present and publish research on Medical Education covering medical, dental, nursing and allied health care professional education. The journal covers undergraduate education, postgraduate training and continuing medical education

\section{Dovepress}

including emerging trends and innovative models linking education, research, and health care services. The manuscript management system is completely online and includes a very quick and fair peer-review system. Visit http://www.dovepress.com/testimonials.php to read real quotes from published authors. 